\title{
RISK FACTOR LEVELS FOR CARDIOVASCULAR DISEASE
}

n 199047 per cent of all deaths in NSW were due to cardiovascular disease (CVD), mainly coronary (or ischaemic) heart disease and stroke. For men there were 7,477 deaths (32 per cent of all deaths) due to coronary heart disease and 1,882 ( 8 per cent) due to stroke; for women the numbers of deaths were 6,820 (34 per cent) from coronary heart disease and 2,937 (14 per cent) from stroke. For the period July 1988 to June 1989 there were 32,227 hospital admissions for coronary disease and 11,841 for stroke, with an estimated cost of more than $\$ 200$ million $^{2}$ CVD is clearly one of the major health problems.

There is considerable geographic variation in mortality from heart disease, with the highest rates in Western and South Western Sydney and the lowest rates in Southern and North Sydney ${ }^{3}$. Hospital admission rates for heart attacks have been found to be significantly higher than the State average in the Central West and North Coast and lowest in Southern, Central and North Sydney.

It is now well established that much CVD can be prevented or delayed by reductions in cholesterol, blood pressure, cigarette smoking and body weight and increases in exercise by individuals and populations, so these risk factors are the targets of many health promotion activities.

The NSW Better Health Program included a project to identify all sources of data on risk factor levels for CVD throughout NSW, to summarise the coverage and comparability of the data, to identify gaps and to summarise the findings.

A total of 43 projects which measured risk factors in populations in 1984-90 was identified. Thirteen were prevalence surveys involving random samples of subjects, 20 were community screenings of self-selected participants and 10 were worksite projects. The graphs show results for selected projects involving 100 or more subjects. These were chosen according to how "representative" of the population the subjects probably were (so worksite screenings are not included) and according to the comparability of measurement methods. Full details are given in reports prepared for the Health Promotion Unit of the NSW Department of Health ${ }^{5,6}$.

Prevalence of cigarette smoking is shown in Figure 1. This varied from more than 70 per cent for the Aboriginal population in Wilcannia to 17 per cent reported from participants in the North Coast Cholesterol Check Campaign (NCCCC). The rates compare with rates of 24 per cent for men and 21 per cent for women found in the National Heart Foundation's survey of capital cities (Australia 1989 NHF). The target of "Health for All Australians" is to reduce the prevalence of smoking to 15 per cent or less by the year 2000 .

Average cholesterol levels (Figure 2) ranged from $6.0 \mathrm{mmol} / \mathrm{L}$ among women measured in an ethnic screening project in the Hunter Region to $4.9 \mathrm{mmol} / \mathrm{L}$ in the North Coast Aboriginal and Islander population. The proportion of people with total cholesterol at or above $6.5 \mathrm{mmol} / \mathrm{L}$ (the level considered by the National Heart Foundation to indicate high risk of coronary heart

\section{FIGURE 1}

PROPORTION OF SMOKERS PROJECT

Wilcannia - Aboriginal
NC - Aboriginal
Western Metropolitan
Greek Study
Wentworth
Wilcannia - Non Aboriginal
Warren
Gosford/Wyong
Western Sydney
NSW Healthy Lifestyle
Hunter $-1988 / 89$
Hornsby/Kuring-Gai
Syd Hospital Screen
Australia - 1989 NHF
Bathurst
Illawarra
Hunter Ethnic Screen
Nth Met Heart Health
Lake Cargelligo
NCCCC

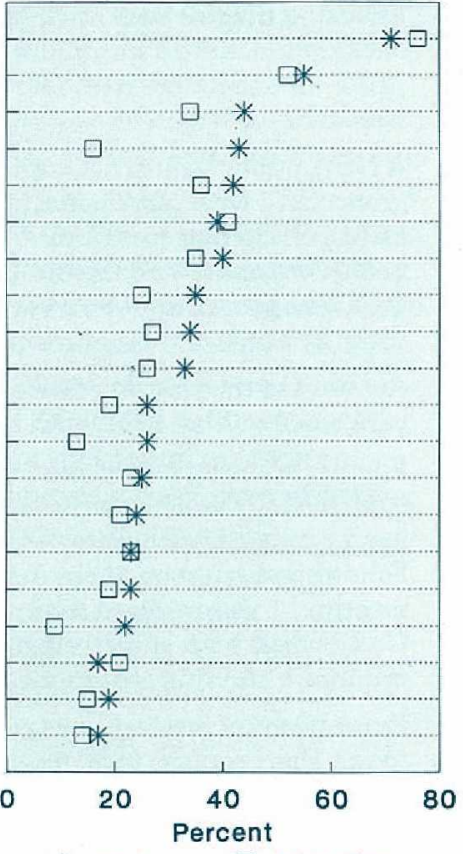

* Males $\square$ Females

\section{FIGURE 2}

MEAN TOTAL CHOLESTEROL PROJECT

Hunter Ethnic Screen

Bourke \& Enngonia

Warren

Wilcannia - Non Aboriginal

Wilcannia - Aboriginal

Hunter $-1988 / 89$

Nth Met Heart Health

Australia $-1989 \mathrm{NHF}$

NCCCC

Gosford/Wyong

Hornsby/Kuring-Gai

Western Sydney

NC - Aboriginal

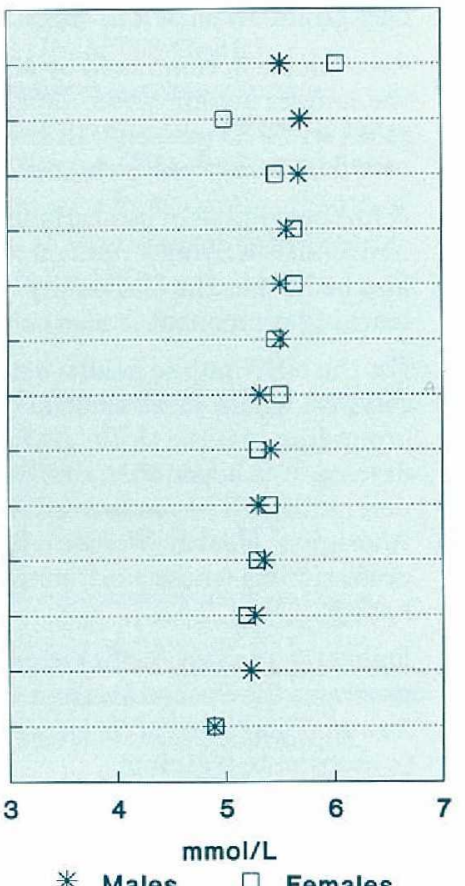

* Males

$\square$ Females

disease) was as high as 25 per cent in Wilcannia and Warren and still more than 10 per cent in the Hornsby/ Kuring-Gai study which had the lowest prevalence. The "Health for All Australians" targets for the year 2000 
FIGURE 3

MEAN DIASTOLIC BLOOD PRESSURE PROJECT

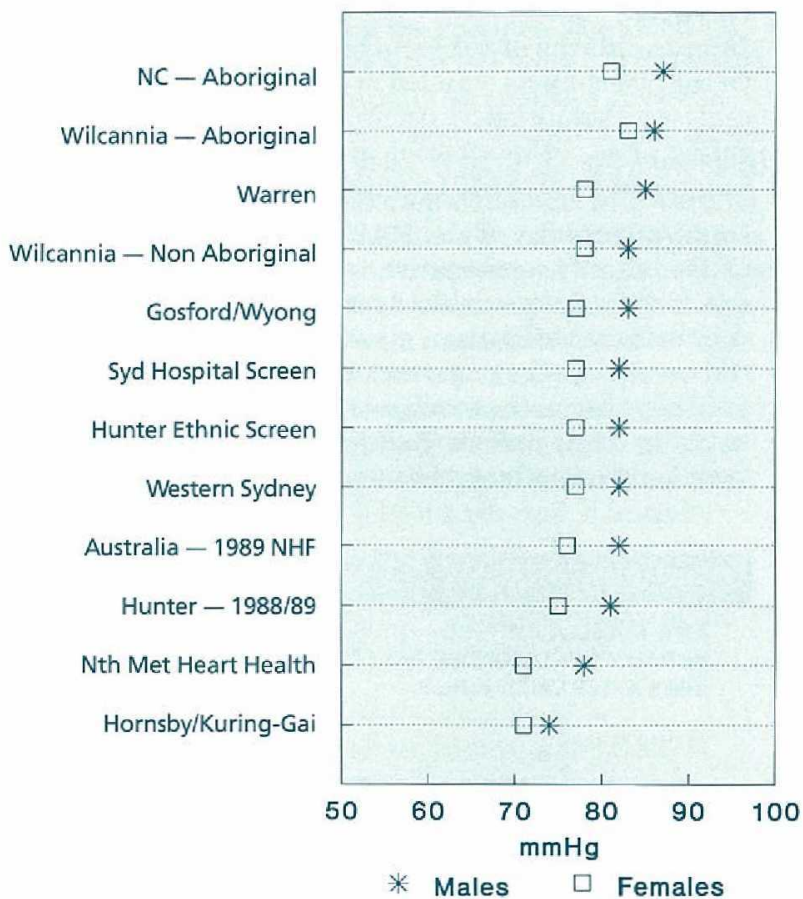

FIGURE 4

MEAN BODY MASS INDEX PROJECT

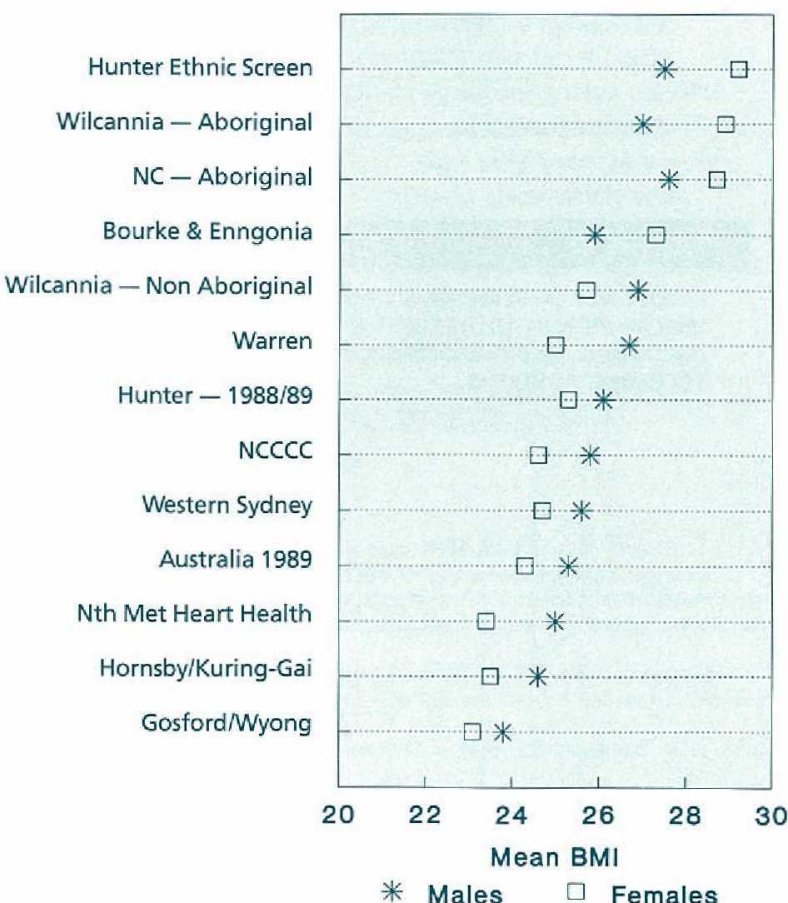

are for cholesterol levels below $4.8 \mathrm{mmol} / \mathrm{L}$ and prevalence of $\geq 6.5 \mathrm{mmol} / \mathrm{L}$ in 8 per cent or less of the population.

Diastolic blood pressure levels are shown in Figure 3.

The highest blood pressure levels were found among the
Aboriginal populations, and everywhere men had higher levels than women. The national target for 2000 is to reduce the proportion of adults with diastolic blood pressure above $90 \mathrm{mmHg}$ to 5 per cent or less. This contrasts dramatically with recent results from the Orana and Far West Region, where 46 per cent of men in Warren and 36 per cent of Aboriginal women in Wilcannia had diastolic blood pressure above $90 \mathrm{mmHg}$. Even in Hornsby/Kuring-Gai 11 per cent of men and 8 per cent of women exceeded this level.

Body mass index (BMI) is an indicator of weight relative to height (Figure 4). Generally men have higher BMI than women except among Aboriginal and ethnic populations. Most of the NSW projects found average BMI above those in the National Heart Foundation survey. Among women the proportions who were overweight or obese included 64 per cent in the Aboriginal population of Wilcannia, 59 per cent in the Greek Good Heart/Good Life project in Sydney, 53 per cent in Purfleet and Forster and 51 per cent in non-Aborigines at Wilcannia. Among men 66 per cent in the Lake Cargelligo project were overweight or obese, as were 62 per cent in the Greek Good Heart/Good Life project.

Levels of physical activity were difficult to compare because of differing methods of defining and categorising exercise. For example, reported prevalence of regular vigorous exercise varied from 1 per cent among Aborigines at Wilcannia to 64 per cent among men and 48 per cent among women at Lake Cargelligo. The need for consistent measurement methods for exercise was one of the recommendations of this review project.

In summary, prevalence of all the major risk factors for CVD was found to be high throughout NSW (which probably explains why, for example, the State has among the highest death rates from heart disease in Australia ${ }^{7}$ ). In particular, risk factor levels were consistently high in Aboriginal populations.

Reports of this project ${ }^{5,6}$, giving details of all the studies reviewed, can be obtained from the Health Promotion Unit, NSW Health Department, Locked Mail Bag 961, North Sydney 2059 (phone 02-391 9585) or the Hunter Region Heart Disease Prevention Program, Centre for Clinical Epidemiology and Biostatistics, The University of Newcastle, Newcastle 2308 (phone 049-21 5507).

Catherine Boyle and Annette Dobson

Department of Statistics,

The University of Newcastle

1. Australian Bureau of Statistics. Causes of Death, Australia 1990 (Catalogue No 3303.0).

2. Dickman P and Gibberd RW. The estimation of tobacco and alcoholcaused hospital admissions and their inpatient costs in NSW hospital 1988/89. Report No 3, 1990. NSW Health Services Research Group. 3. NSW Health Department, NSW Health Indicators Health Areas and Regions. Heart Disease 1990. NSW Health Department. Fact Sheet No 9011. 4. NSW Health Department, NSW Health Indicators Health Areas and Regions. Acute Myocardial Infarction hospitalisation. NSW Health and Regions. Acute Myocardial In

Department. Fact Sheet No 9111. NSW: a summary of available data in 1991. Department of Statistics, University of Newcastle

6. Hunter Region Heart Disease Prevention Program. Studies of Cardiovascular Disease Risk Factors in NSW, July 1991, University of Newcastle.

7. Sexton P, Woodward D, Gilbert N, et al. Interstate differences in trends in coronary mortality and risk factors in Australia. Med J of Aust 1990; 152:531-534. 